\title{
SALINITY AND THE GLOBAL WATER CYCLE
}

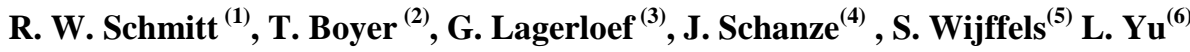 \\ ${ }^{(1)}$ Woods Hole Oceanographic Institution, Woods Hole, MA, 02543, USA Email: rschmitt@whoi.edu \\ ${ }^{(2)}$ Nat. Ocean. Data Center, NOAA, Silver Spring, MD, USA Email: boyer@nodc.noaa.gov \\ ${ }^{(3)}$ Earth and Space Research, Seattle,WA USA, Email: glagerlo@jpl.nasa.gov \\ ${ }^{(4)}$ Woods Hole Oceanographic Institution, Woods Hole, MA, 02543, USA. Email: schanze@mit.edu \\ ${ }^{(5)}$ CSIRO, Hobart, Tasmania, Australia Email: Susan.Wiiffels@csiro.au

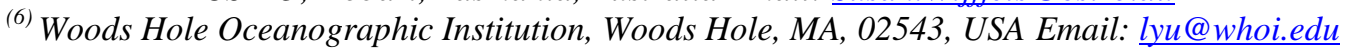

\begin{abstract}
The global water cycle is mainly an ocean-atmosphere phenomena, yet most studies have focused on the much smaller terrestrial component. Here we show that sea surface salinity has much to tell us about the global water cycle. We review evidence from oceanic salinity data that the water cycle is changing and connect it to trends in estimates of surface fluxes. We also discuss the important interplay between surface water fluxes and upper-ocean mixing processes that arises from buoyancy physics. Connections to the stability of the thermohaline circulation are treated. The strong nonlinear dependence of the vapor pressure of water on temperature leads to predictions of an enhanced hydrologic cycle resulting from global warming, which has helped to motivate plans for new salinity sensing satellites SMOS (Soil Moisture and Ocean Salinity) and Aquarius. The in-situ observational requirements for these programs, along with the opportunities provided for new field programs examining the details of the upper-ocean processes affecting sea surface salinity, provide strong motivation to expand our observational capabilities for salinity.
\end{abstract}

\section{INTRODUCTION}

No element of the climate system is as important to society as the global water cycle, yet it is still poorly understood, primarily because most of it occurs over the vast and under-sampled oceans. Salinity is the signature of the water cycle in the ocean, and the oceanographic community has much to offer to advance our understanding of the water cycle and its variability. Estimates of evaporation and precipitation over the ocean suggest an enhancement of the water cycle from the mid-1970s to the present, a trend that is supported by available surface salinity observations. This may be consistent with expectations from global warming, but the decadal climate variability of the ocean is clearly involved as well. In fact, variability in precipitation on land is known to be closely linked to the dominant decadal modes of ocean variability. Thus, improved understanding of oceanic decadal climate would be of great predictive value for freshwater supplies for population centers and the agricultural sector. Trends in high latitude surface salinity have been popularly suggested as an agent of abrupt change in ocean circulation and climate, but we show that such assumptions are critically dependent on ocean mixing rates. These could respond to freshening in unexpected ways to make abrupt climate change less rather than more likely. Oceanographers need to greatly expand, amplify and sustain salinity observation systems in the years ahead.

It is a commonplace statement that the oceans are the main thermal regulating element of the climate system, but it is also true that they are the reason we have freshwater supplies that have allowed terrestrial life to evolve into our large and highly mechanized human civilization. Nearly $90 \%$ of global evaporation comes from the oceans, so its central role in the global water cycle cannot be ignored. Within the ocean, the water cycle has a significant impact on salinity, and thus density, circulation, stratification and mixing. In general, salinity variability accounts for about half as much of the density variance as temperature, usually in a counter-acting way. In this paper, we review some of the basic elements of salinity variability and its relation to the global water cycle, trends in both, and suggest that an improved understanding of the role of salinity in the climate system could be key to better decadal forecasts of water supplies.

\subsection{Mean state of the water cycle and salinity}

Wust [1] illustrated the essential linkage of the water cycle to ocean salinity, when he plotted sea surface salinity (SSS) against estimates of evaporation minus precipitation (E-P). He suggested a simple balance obtained between vertical mixing and E-P that yielded a linear relationship between the two. We now have better data and a better appreciation for the role of advection, but the essential truth remains, surface waters are saltier under the highly evaporative mid-latitude trade wind regions, fresher in the precipitation zones at high latitudes and under the Inter-Tropical Convergence Zone (ITCZ). Figs. 1.a and 1.b illustrate the general patterns of both E-P and SSS for the global ocean. Other fundamental features such as the high salinities of the Atlantic relative to the Pacific, and the freshness of 

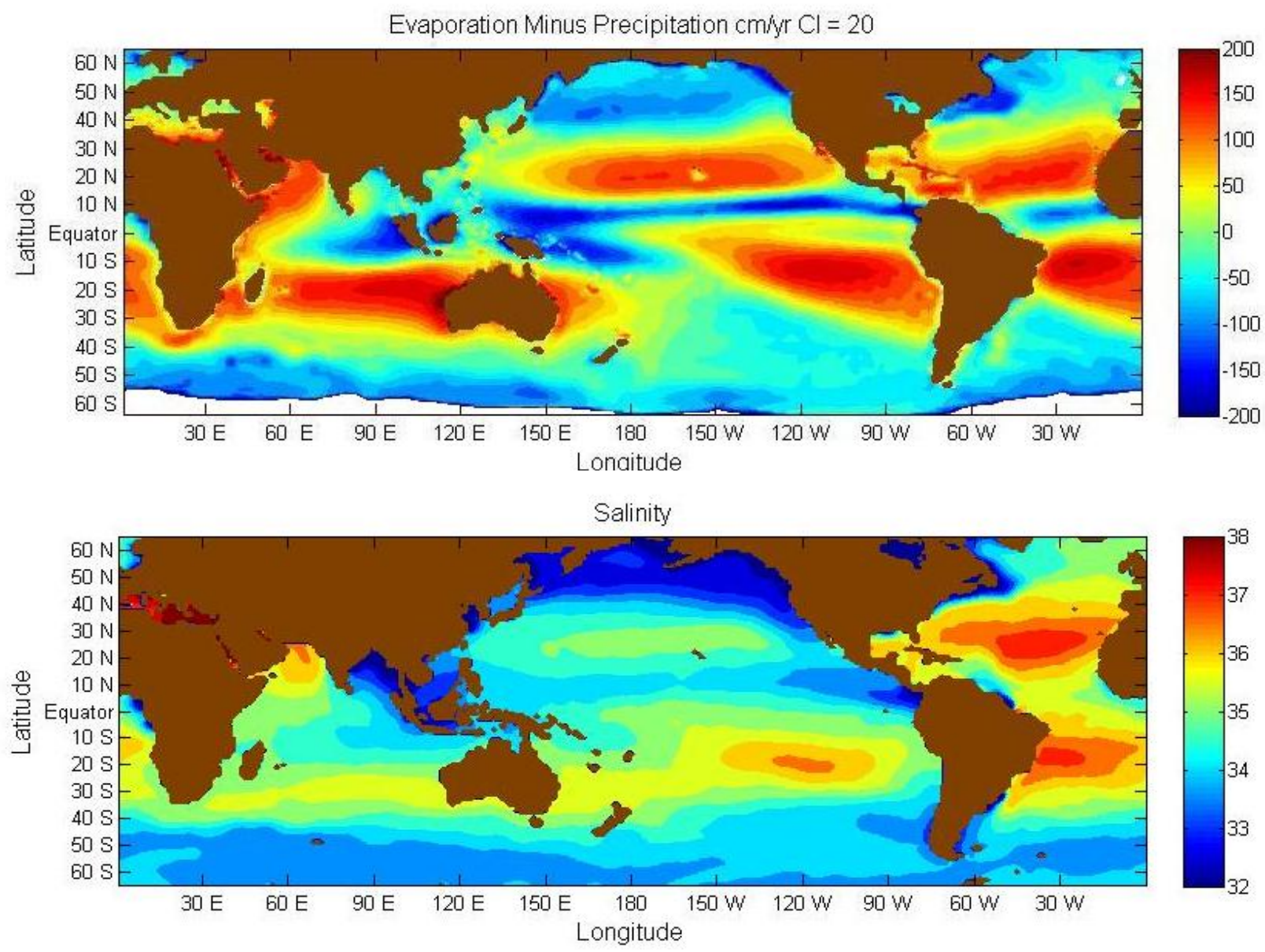

Figure 1.a (top) A new estimate of annual average evaporation - precipitation, based on the evaporation climatology of Yu and Weller [2] and satellite-based precipitation estimates from the Global Precipitation Climatology Program (GPCP, available at: http://precip.gsfc.nasa.gov/). The units are centimeters per year. Color scale changes occur every $20 \mathrm{~cm} / y$ r. Fig. 1.b (bottom). Average surface salinity of the world ocean, contoured from the World Ocean Database of NODC (National Ocean Data Centres).

some coastal regions are also worth noting. Low coastal salinities are invariably related to river and groundwater discharges or melting glaciers, but the Atlantic-Pacific salinity contrast is worth some discussion. In part, this salinity contrast is due to the narrowness of the Atlantic; a greater fraction of its surface area is under the influence of dry continental air [3]. But the arrangement of the continents also plays a role, moisture is easily transported to the Pacific across the Central American Isthmus [4], but there is little transport from the Indian Ocean to the Atlantic, and little significant moisture flux from the Sahara desert. Warren [5] also notes that the coolness of the North Pacific relative to the North Atlantic will lead to decreased evaporation as a consequence of the nonlinear dependence of the vapor pressure of water on temperature (at $5^{\circ} \mathrm{C}$ the vapor pressure is less than a third of its value at $25^{\circ} \mathrm{C}$ ). The resulting higher salinities and densities help to maintain the Atlantic's status as a site for deep convection, with the thermohaline circulation causing an anomalous northward heat transport in the South Atlantic, thus sustaining the positive feedback between higher temperatures and more evaporation [6].

The spatial patterns and inter-basin contrasts of Evaporation minus Precipitation lead to a need for the oceans to redistribute water around the globe, in order to avoid sea level trends of several meters per year. The redistribution of water by the oceans has been treated in [7], [8], [9], [10], and [11]. The basic pattern of meridional transport arises from the need to return water from the precipitation regions of the tropics and high latitudes to the mid latitude evaporation zones. The interbasin transport of water vapor from Atlantic to Pacific results in a fresher Pacific that stands about 50 $\mathrm{cm}$ higher than the Atlantic. This head contributes to the flow of water through Bering Strait, providing fresher water to the Arctic and returning water to the Atlantic. Reference [7] sketched out the consequences for global transports of water and salt. The transports there are treated as absolutes, rather than freshwater 
anomalies relative to a reference salinity as is often done for enclosed seas. The resulting non-divergent transport of salt around the Americas is one consequence. Such circulation schemes for the global water cycle are quite different than those originally envisioned by hydrologists [12]. Most recently, [11] has described the shallow, deep and throughflow components of the oceanic transport of freshwater, and how the freshwater cycle maintains the salinity differences between basins and contributes to water mass formation. She finds that the Bering Strait throughflow makes a minor contribution to the Atlantic freshwater balance but is very important to the North Pacific.

We also now appreciate that there are dynamical consequences of the surface mass losses and gains of freshwater over the ocean. The "Goldsbough-Stommel" circulation of Sverdrup interior flows driven by surface water gains or losses, with western boundary currents to close the circulation, was sketched by [13]. They combine this with the interbasin mass transports to describe a current system that yields a $2 \mathrm{~Sv}$ southward flow to counter the Gulf Stream in the western North Atlantic and suggest that it may contribute to a southward displacement of the separation latitude. Thus, the current systems induced by the water cycle cannot be neglected.

\section{TRENDS IN THE GLOBAL WATER CYCLE AND SALINITY}

The evaporation and precipitation products now available (Fig. 1.a) are currently being scrutinized for stationarity of the data sets and other issues. Observing systems change over time and the introduction of various satellites products have improved the estimation of precipitation as well as winds and water vapor content for evaporation. Tends in several evaporation products can be seen in Fig. 2. The global average annual evaporation is estimated to have reached a minimum in the late 1970's in all four products and has been generally increasing since then in three of the four climatologies. The reliability of such global trends is hard to assess; [14] ascribes it to increasing winds in her OA Flux product. An upward trend in evaporation agrees with expectations from global warming; as the atmosphere warms the greater mobility of water molecules with increasing temperature leads to an increase in the vapor pressure. One way the oceanographer can contribute to this issue is by examining the surface salinity trends for the same time periods. Fig. 3.a shows a map of the global difference in surface salinity from the late 1970s to the early 2000s from the NODC (National Ocean Data Centres) data archives. A widespread salinification in the Atlantic can be seen along with a general freshening pattern in both northern and western tropical regions of the Pacific. A similar pattern is observed in the 50 year SSS trends analysed by [15] in Fig. 3.b. This suggests that the upward trend in evaporation reinforced the zonal transport of water vapor from Atlantic to Pacific and possibly reinforced the meridional transport patterns in the Pacific. The salinity trends represent far better evidence for a changing global water cycle than any terrestrial rainfall or river flow data, most of which show little trend [16]. But we must also acknowledge that the flux estimates remain a challenging area of research and that the salinity databases remain sparse. Monitoring the future evolution of salinity in the global ocean will be an important contribution that oceanographers can make to the understanding of global climate change.

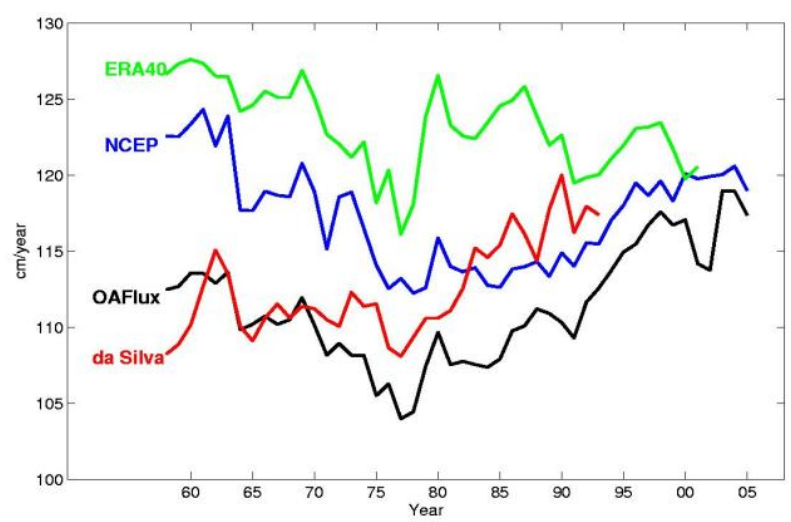

Figure 2. Global annual average evaporation from several data products, including the OA Flux of Yu and Weller [2]. A minimum was reached in the late 1970's and a general upward trend is estimated since then in 3 of the 4 estimates.

The apparent trends in salinity and possibly evaporation may be linked to the expected enhancement of the water cycle with global warming. However, the relationship is complex. While precipitable water may increase at the same rate as the saturation specific humidity $(\sim 7 \%$ per degree $\mathrm{K}$ of warming), the changes in evaporation and precipitation are likely strongly constrained by energetics to $\sim 2 \%$ increase per degree of warming [17]. This would suggest that the strong trends in observed evaporation in 3 of the 4 data sets since the mid $70 \mathrm{~s}$ (Fig. 2) are unrealistic. It is important to get these trends right since the water cycle plays a substantial role in the Earth's radiation balance (water vapor being the major greenhouse gas), in the transport of heat from the tropics to the poles, and in the weathering processes that help sequester $\mathrm{CO}_{2}$ on long time scales [18]. 


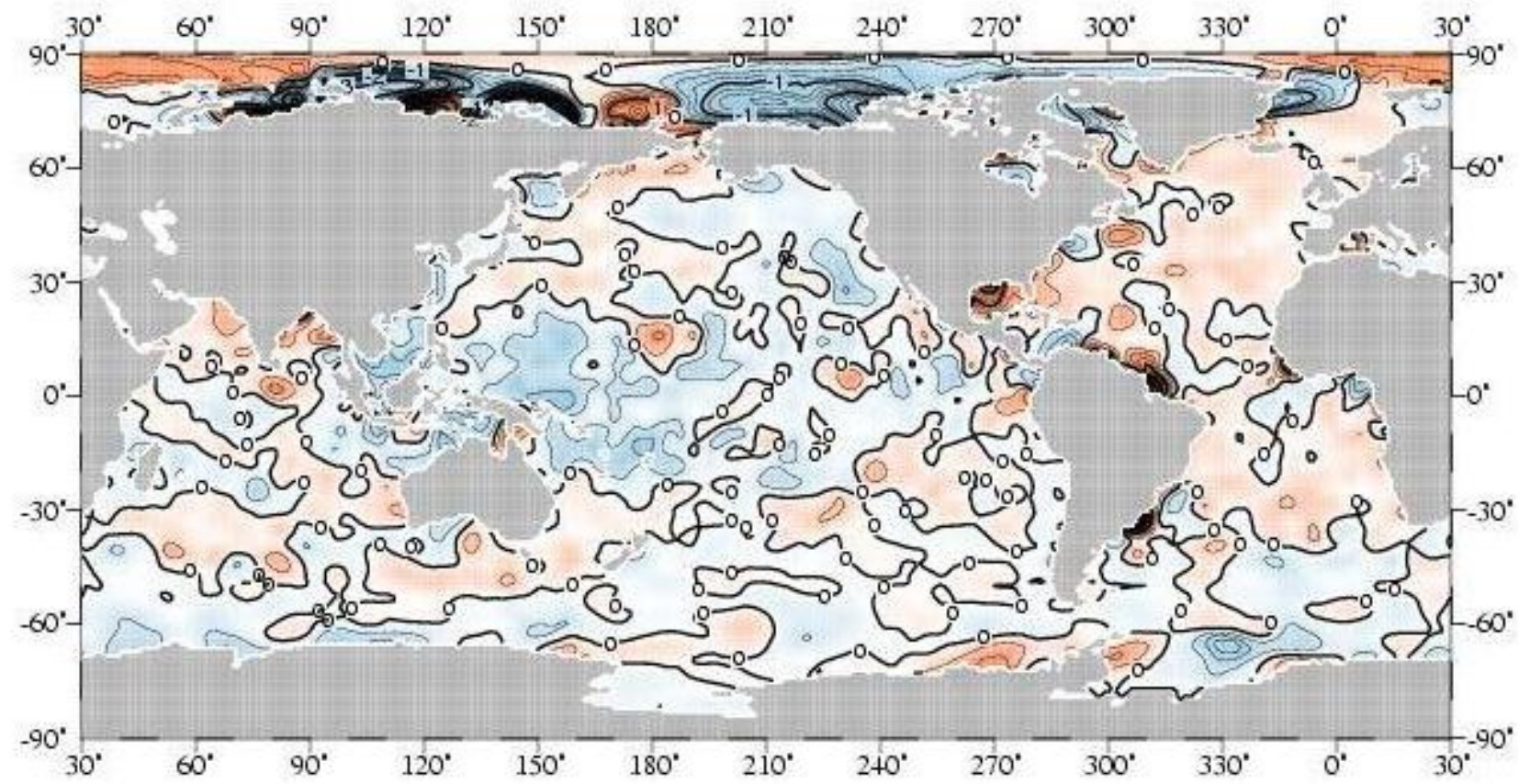

Contont intetval: 0.25

Figure 3.a The sea surface salinity anomaly difference between the pentads 2000-2004 and 1975-1979. Orange $=$ positive, blue $=$ negative, Contour Interval $=0.25$.

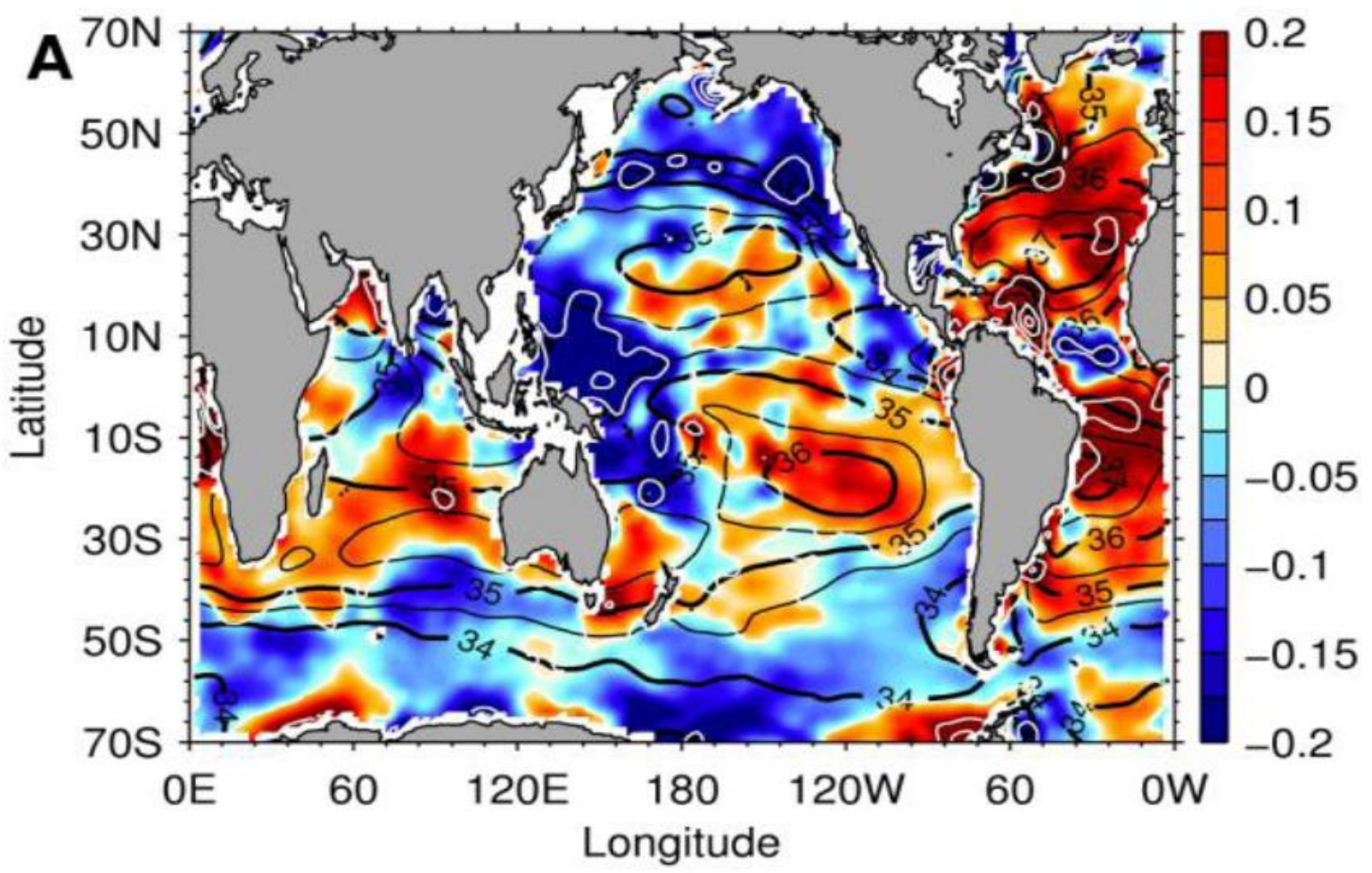

Figure 3.b. Fifty-year trends in surface salinity from linear least squares fits estimated by [15]. Subtropical salinification, tropical and high latitude freshening, and an enhanced contrast between Atlantic and Pacific all support an intensification of the global water cycle. 


\section{SALINITY VARIABILITY}

In addition to long-term trends in salinity, there are available a few continuous records of salinity from time series stations. These are challenging to maintain and require lots of human intervention. But the classic time series from the Labrador Sea Weather Station Bravo from 1964-1974 [19] and the still-ongoing time series from Weather Station Mike in the Norwegian Sea show the strength of seasonal and interannual changes in salinity [20]. They observe both the seasonal cycle and interannual to decadal variability to have an amplitude of $\sim 0.1$ at a depth of $50 \mathrm{~m}$.
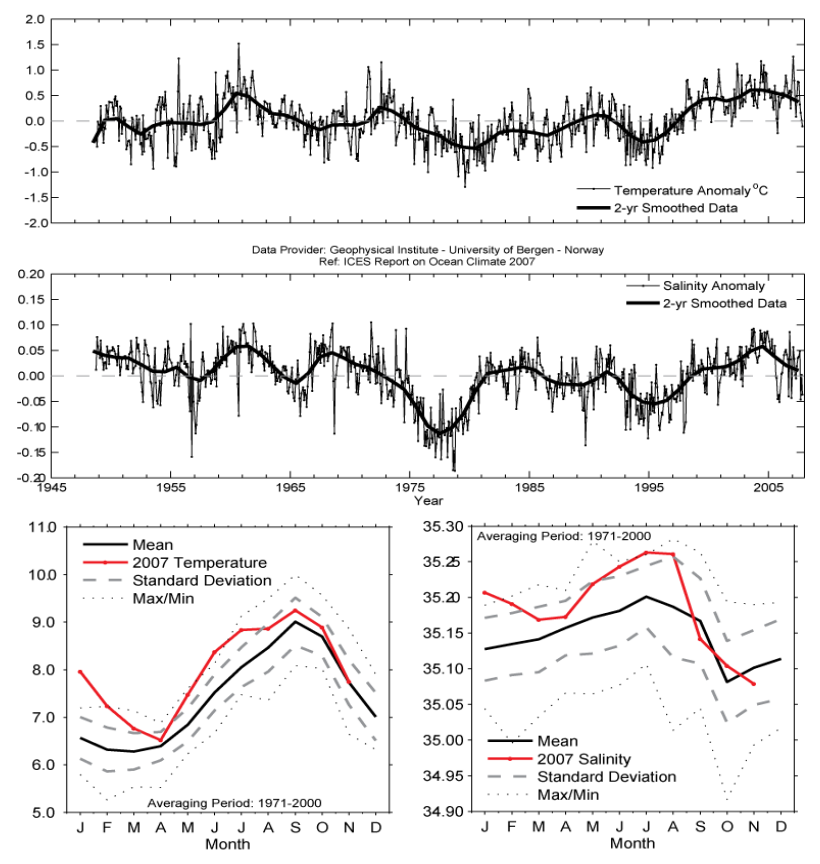

Figure 4. Temperature and Salinity variability at $50 \mathrm{~m}$ depth at Ocean Weather Station M, one of the few longterm salinity records maintained since the 1940s. Top panel, monthly temperature anomaly, with 2-year smoothing. Middle panel, monthly and 2-year smoothed salinity anomaly. Bottom panels, annual average cycles of temperature and salinity, their standard deviations and minimums and maximum ranges as well as the 2007 data.

Even larger salinity variability near Bermuda has been noted by [21]. They link the variability to changes in E$\mathrm{P}$ and note that E-P in the Atlantic is well correlated with the Nino 3 index, especially since 1975 . This is a period when the Pacific Decadal Oscillation has been in a positive phase. However, satellites that contribute to our estimates of both evaporation and precipitation began to significantly improve surface flux estimates about the same time, so in-homogeneities in the flux estimate time series may also contribute to the improved correlations.

\section{SALINITY AND CLIMATE CHANGE}

Several studies have suggested that decadal climate predictability may be possible in variables associated with the thermohaline circulation of the North Atlantic Ocean, which can be monitored [22] and [23]. In particular, salinity variations may be particularly helpful, as freshwater anomalies can modulate the depth of convection in certain regions [24] and [25]. On longer time scales, it has often been suggested that an intensified water cycle could freshen surface waters in the North Atlantic sufficiently to slow or even shut down the thermohaline circulation. This has been suggested by paleo-oceanographic data that infer abrupt North Atlantic circulation changes were induced by massive discharges of glacial meltwater when ice-dams broke [26]. Many climate models project a slowing down of the Atlantic meridional circulation [27] and [28]. However, such models are suspect on several grounds. For one, they do not properly model the coasthugging flow of a coastal freshwater discharge, but rather impose it as a general "hosing" of the entire North Atlantic. Secondly, they do not incorporate the effects of changing salinities on the stratification and thus the mixing rate of the ocean. That is, climate models fail to take account of the spatial and temporal variability in the vertical mixing coefficient $K_{\square}$. Polzin et al [29] documented the broad spatial variations in mixing rate associated with topography and [30] noted the variation with tidal forcing. The mixing rate depends on the turbulent energy dissipation rate as well as the stratification through the formula [31]:

$$
K_{\rho}=0.2 \varepsilon / N^{2}
$$

Models assume constant and uniform $K_{\rho}$ when clearly the stratification and turbulent dissipation rate could be changing. Aside from getting the deep circulation wrong because they do not represent the spatial variations in $K_{\rho}$, models have not generally factored in the response in the mixing rate due to changing stratification. That is, we expect that the energy sources for deep ocean mixing (tides) will remain constant over the times scales of interest but the stratification will certainly respond to changing salinities. In fact, the salinity changes observed in the North Atlantic have penetrated into the deep ocean [32], so a changing stratification is to be expected. Freshening of the deep waters will clearly tend to decrease $N^{2}$ with respect to the overlying intermediate waters, so an increase in $K_{\rho}$ is predicted.

The response of the thermohaline circulation to both changing freshwater forcing and varying diffusivity has been examined with both theory and numerical runs by Zhang et al [33]. They obtained a relationship in the 
freshwater forcing and diffusivity plane that separated the thermal mode from the haline (reversed) mode. That is, with larger mixing rates a larger freshwater forcing could be tolerated before collapse of the thermal mode. Fig. 5 below illustrates the theoretical relationship along with contours of the meridional overturning strength. While conventional models would keep the diffusivity fixed and rapidly increasing freshwater fluxes could cause collapse of the MOC (Meridional Overturning Circulation), a diffusivity that responded to a slowly increasing fresh- water flux could actually cause the MOC to strengthen according to [34] and [35]. This counterintuitive result arises from the sensitivity of the stratification and mixing rate to salinity, and is just one example of how the freshwater cycle impacts ocean dynamics. Monitoring of mixing rates as proposed by [36] along with changing salinities thus has much to recommend it. The potential trade-offs between oceanic heat and water transports by the MOC and atmospheric transport by storms and the unknown role of salinity in modulating the ocean thermohaline circulation suggests that we have much motivation to come to a better understanding of these key climate processes.

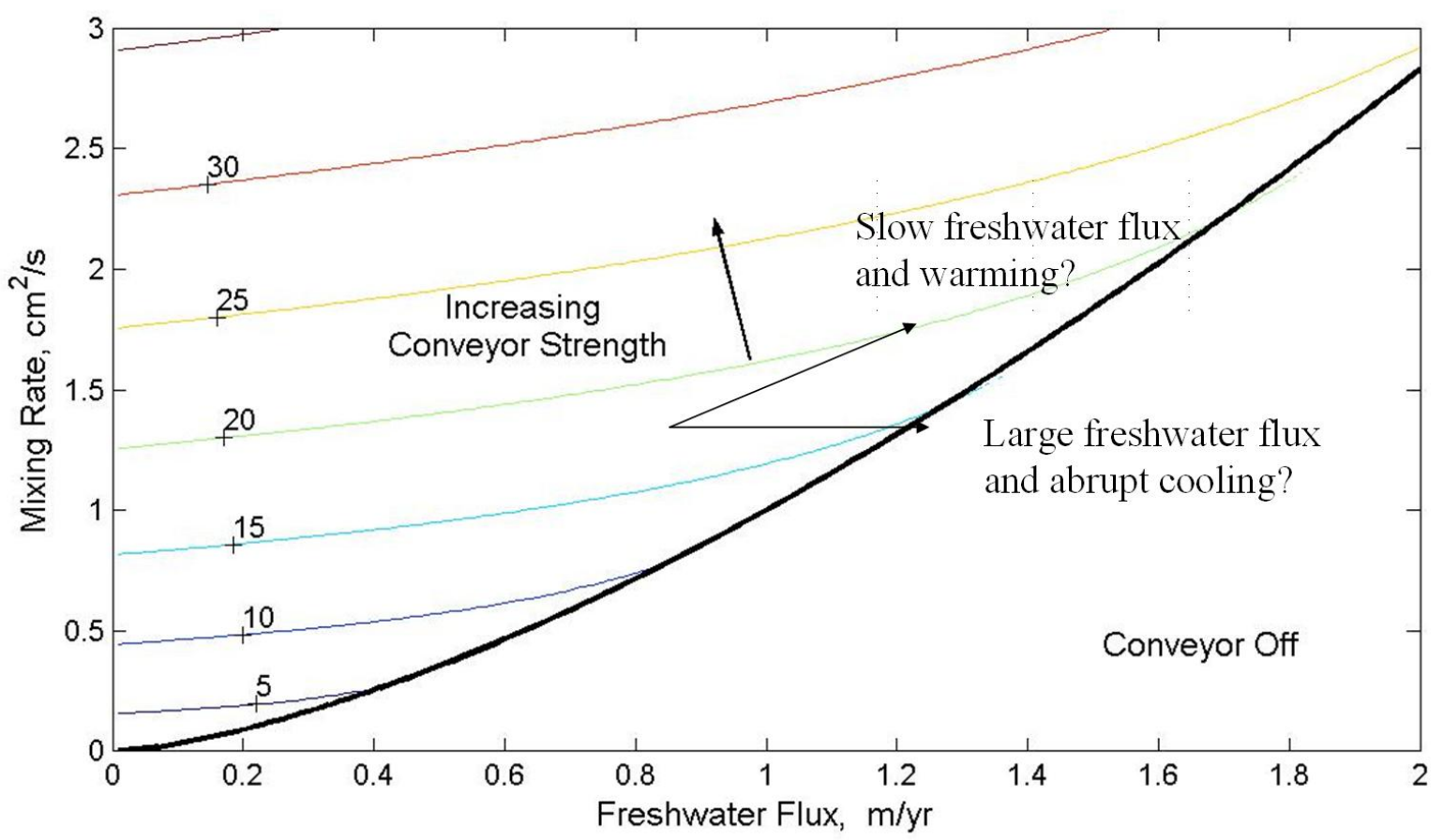

Figure 5. Contour plot of the strength of the meridional overturning circulation (MOC, in Sverdrups) as a function of the vertical mixing rate and the high latitude freshwater flux magnitude, according to the analysis of Zhang et al, [37]. Points below the black curve are in the "haline" mode, with the direct thermal mode (conveyor) in its off state. Points above the black curve are in the direct thermal mode, with the strength of the MOC varying with the contours as shown. A large increment in freshwater flux due to a

collapsing ice dam might push the system over the edge and shut off the thermal mode, but a slow freshwater flux increase (as we are experiencing with global warming) could change the deep stratification so as to cause an increase in the mixing rate that leads to a stronger overturning circulation and a warmer rather than cooler North Atlantic. Thus, it is important to understand the response of all aspects of ocean dynamics to changing freshwater forcing before attempting to predict the future state of the meridional overturning circulation. 


\section{THE OCEANS AND TERRESTRIAL RAINFALL}

Of course, one reason for advancing understanding of the water cycle is the freshwater supply for civilization. The oceans are by far the source of most atmospheric moisture, and the mobility of water vapor molecules in air is a strongly increasing function of temperature. It has long been know that SST (sea surface temperature) distributions are useful predictors of rainfall on land [38] and [39]. Karnaskas and Busalacchi [40] have related eastern tropical Pacific surface temperatures to Central American rainfall. Recently, Shanahan et al, [41] found that Atlantic SST variability is largely responsible for the patterns of drought in the West Africa. Using lake sediment data and tree ring reconstructions of the Atlantic Multidecadal Oscillation (AMO), they find that the West African Monsoon is in phase and coherent with the AMO on times scales between 30 and 50 years. The sense is such that warm SST anomalies in the Atlantic produce increased precipitation over West Africa. Recently, Ummenhofer et al [42] found that it is Indian Ocean SST patterns (the absence of the negative phase of the east-west Indian Ocean Dipole in SST) that controls the occurrence of drought in south and west Australia. Previous work had focussed on El Nino, but this latest finding provides a much more robust estimator of rainfall. Clearly, advances in predictability of oceanic SST will be very valuable in agriculture and water use planning. The SST-rainfall connection has been securely established in a number of case studies and it now must be more fully explored and utilized for improved long-term predictability of rainfall. Obviously, advances in ocean monitoring, modelling and prediction will have great value for extending the time scales of rainfall predictability. Salinity measurements, with their intrinsic linkage to the water cycle will be a key variable in future improvements. The local role of salinity in modulating upper ocean stratification, mixing, and heat storage, as well as in the large-scale decadal predictability problem outlined earlier, is a strong motivation to expand salinity-observing systems. The strong linkage between oceanic conditions and the occurrence of drought or deluge on land provides strong motivation for the oceanographer to overcome the observational challenges of expanded salinity measurements.

\section{THE SALINITY MEASUREMENT CHALLENGE}

Clearly, a remarkable success has been achieved with salinity measurements in the Argo (Array for Real-time Geostrophic Oceanography) float program [43]. The continuously immersed conductivity sensors used on the floats have proven to be more reliably accurate over multi-year time periods than most sensors deployed from ships, which must break the ocean surface twice with each cast [44]. The avoidance of surface films and the lack of sunlight at the float parking depth have much to do with this success. A central goal of expanding salinity measurements should be to develop a better understanding of what these salinity patterns are telling us about the water cycle. The Argo float (Global array of free-drifting profiling floats) program is rapidly adding to the available subsurface salinity data. However, in order to maintain calibration, the CTD (conductivity-temperature-depth) is turned off $5 \mathrm{~m}$ beneath the surface. Thus, data on the actual surface salinity, which will be most closely tied to the water cycle, is not growing as fast as we would like. SSS data will be necessary to calibrate/validate the new salinity sensing satellites, SMOS (Soil Moisture and Ocean Salinity) and Aquarius [45]. Argo floats also have a 10day gap between surfacings, so data is sparse.

A great potential exists to expand surface salinity measurements using sensors deployed on surface drifters. New techniques must be developed to make long-term salinity measurements more readily achievable from surface drifters and upper-ocean moorings. Reverdin et al, [46] have had some success with drifter-deployed sensors, though some issues with surface heating and temporal drift remain. This is a technology that requires additional development and testing. However, the numerous and widely distributed surface drifters of the Global Drifter Program provide an exceptional opportunity for continuous monitoring of the global surface salinity and a global SSS measurement program for drifters ought to be initiated. Similarly, maintenance and expansion of thermosalinographs on volunteer observing ships [47] ought to be encouraged. The challenges here are for on-going maintenance and calibration of the shipboard sensor systems; this requires a continuous commitment to personnel and a quality control program. The operators of the moored sites of the ocean observing system [48 and 49] should also make a concerted effort to maintain long-term salinity time series; as such, records can provide important long-term reference records for documentation of the changing salinity field. Finally, in all cases we note the need for ongoing quality control efforts, models and forecasts can only be as good as the data provided to them (garbage in yields garbage out). Salinity remains a challenging variable and quality control efforts must keep pace with expanding data sources [50].

Society has a great need to advance its understanding of the changing global water cycle. With the vast majority of the water cycle occurring over the oceans, it is clear that ocean measurements of SSS will be an essential element of expanding that understanding. The advent of salinity sensing satellites SMOS and Aquarius, and expanding in-situ salinity monitoring capabilities will 
facilitate a special focus on the global water cycle in the next decade. Future modelling and prediction capabilities for drought or deluge on land will depend on how well we are able to improve ocean monitoring capabilities.

\section{ACKNOWLEDGMENTS}

RWS acknowledges the support of the National Science Foundation with grant \#OCE-0647949 and the National Aeronautics and Space Administration with grant \#NNX10AE196.

\section{REFERENCES}

1. Wűst, G. 1936. Oberflachensalzgehalt, Verdunstung und Niederschlag auf den Weltmeere, Landerkundliche Forschung, Festschrift f. Norbert Krebs.

2. Yu, L. and R. A. Weller, 2007. Objectively Analyzed airsea heat Fluxes for the global oce-free oceans (19812005). Bull. Ameri. Meteor. Soc., 88, 527-539.

3. Schmitt, Raymond W., Phillip S. Bogden, and Clive E. Dorman, 1989. Evaporation minus precipitation and density fluxes for the North Atlantic. Journal of Physical Oceanography, 9(9), 1208-1221.

4. Weyl, P. K., 1968. The role of the oceans in climatic change: a theory of the ice ages, Meteorological Monograph 8 (1968), pp. 37-62.

5. Warren, B. A., 1983. Why is no deep water formed in the North Pacific? J. Mar. Res., 41, (2), pp. 327-347(21).

6. Haupt, B. J., D. Seidov, 2007. Strengths and weaknesses of the global ocean conveyor: Inter-basin freshwater disparities as the major control. Progress In Oceanography, 73, (3-4), 358-369.

7. Wijffels, S.E., Schmitt, R.W., Bryden, H.L. and Stigebrandt, A., 1992. Transport of freshwater by the oceans. Journal of Physical Oceanography 22, 155-162.

8. Schmitt, R. W., 1995. The ocean component of the global water cycle. U.S. National Report to International Union of Geodesy and Geophysics, 1991-1994, Supplement to Reviews of Geophysics, pp. 1395-1409.

9. Wijffels, S.E., 2001. Ocean transport of fresh water. In: Siedler, G., Church, J., Gould, J. (Eds.), Ocean Circulation \& Climate. Academic Press, pp. 475-488.

10. Dai, A. and K. E. Trenberth, 2002, Estimates of Freshwater Discharge from Continents: Latitudinal and Seasonal Variations. Journal of Hydrometeorology, 3, 660-687.

11. Talley, L., 2008. Freshwater transport estimates and the global overturning circulation: Shallow, deep and throughflow components. Progress in Oceanography 78 (2008) 257-303.

12. Baumgartner, A. and E. Reichel. 1975. The World Water Balance. Elsevier, New York, 179 pp.
13. Huang, R. X. and R. W. Schmitt, 1993. The GoldsbroughStommel circulation of the world ocean. Journal of Physical Oceanography, 23(6), 1277-1284.

14. Yu, L., 2007: Global variations in oceanic evaporation (1958-2005): The role of the changing wind speed. $J$. Climate, 20(21), 5376-5390.

15. Durack, P. J. and S. E. Wijffels, 2010. Fifty-Year Trends in Global Ocean Salinities and Their Relationship to Broad-Scale Warming. J. Climate, 23, 4342-4362. doi:10.1175/2010JCLI3377.1.

16. Dai, A., T. Qian, K.E. Trenberth, and J.D. Milliman, 2009: Changes in Continental Freshwater Discharge from 1948 to 2004. J. Climate, 22, 2773-2792.

17. Schneider, T., P. A. O'Gorman and X. Levine. 2009. Water Vapor and the Dynamics of Climate Changes. Rev.Geophy.s, 48, RG3001, doi:10.1029/2009RG000302.

18. Pierrehumbert, R. 2002. The hydrologic cycle in deep-time climate problems. Nature, 419, 191-198.

19. Lazier, J. R., Oceanographic conditions at ocean weather ship Bravo, 1964-1974, Atmos. Ocean, 18, 227-238, 1980 .

20. Holliday, N. \& Co-Authors (2010). "The ICES Working Group on Oceanic Hydrography: Building on Over 100 Years of North Atlantic Observations" in these proceedings (Vol. 2), doi:10.5270/OceanObs09.cwp.43.

21. Gordon, A. and C. F. Guilivi, 2008. Sea surface salinity trends over 50 years within the subtropical North Atlantic. Oceanography, 20 (1), 20-29.

22. Griffies, S. M. and K. Bryan, 1997. Predictability of North Atlantic Multidecadal Climate Variability, Science, 275, 181-184.

23. Grötzner, A., M. Latif, A. Timmermann, and R. Voss, 1999: Interannual to Decadal Predictability in a Coupled Ocean-Atmosphere General Circulation Model. $J$. Climate, 12, 2607-2624.

24. Dickson R. R., Meincke J., Malmberg S.-A., Lee A. J., 1988. The great salinity anomaly in the northern North Atlantic 1968-1982. Progress in Oceanography, 20, (2), 103-151.

25. Dickson, R., J. Lazier, J. Meincke, P. Rhines, and J. Swift, 1996. Long-term coordinated changes in the convective activity of the North Atlantic. Progress in Oceanography Volume 38, Issue 3, 1996, Pages 241-295.

26. Alley, R.B., J. Marotzke, W.D. Nordhaus, J.T. Overpeck, D.M. Peteet, R.A. Pielke Jr., R.T. Pierrehumbert, P.B. Rhines, T.F. Stocker, L.D. Talley, and J.M. Wallace. 2003. Abrupt Climate Change. Science 99(5,615):2,0052,010 .

27. Rahmstorf, S., 2000: The thermohaline ocean circulation a system with dangerous thresholds? Climatic Change, $46,247-256$.

28. Stouffer, R. J., J. Yin, J. M. Gregory, K. W. Dixon, M. J. Spelman, W. Hurlin, A. J. Weaver, D, M. Eby, G. M. Flato, H. Hasumi, A. Hu, J. H. Jungclaus, I. V. Kamenkovich, A. Levermann, M. Montoya, S. 
Murakami, S. Nawrath, A. Oka, W. R. Peltier, D. Y. Robitaille, A. Sokolov, G. Vettoretti, and S. L. Webero. 2006. Investigating the Causes of the Response of the Thermohaline Circulation to Past and Future Climate Changes. Journal of Climate, 19, 1365-1387.

29. Polzin, K .L., J. M. Toole, J. R. Ledwell, and R. W. Schmitt, 1997. Spatial variability of turbulent mixing in the abyssal ocean. Science, 276, 93-96.

30. St. Laurent, Louis C., John M. Toole, and Raymond W. Schmitt, 2001. Buoyancy forcing by turbulence above rough topography in the abyssal Brazil Basin. Journal of Physical Oceanography, 31, 3476-3495.

31. Osborn, T., 1980: Estimates of the Local Rate of Vertical Diffusion from Dissipation Measurements. J. Phys. Ocean., 10, 83-89.

32. Curry, R., R. R. Dickson and I. Yashayaev, 2003. A change in the fresh water balance of the Atlantic over the past four decades. Nature 426(6968):826-829.

33. Zhang, J., R. W. Schmitt, and R. X. Huang, 1999. The relative influence of diapycnal mixing and hydrologic forcing on the stability of the thermohaline circulation. Journal of Physical Oceanography, 29(6), 1096-1108.

34. Nilsson, J. and G. Walin, Freshwater forcing as a booster of thermohaline circulation, Tellus 53A (2001), pp. 628641.

35. Huang, R. X., 1999. Mixing and energetics of the thermohaline circulation. Journal of Physical Oceanography, 29(4), 727-746.

36 MacKinnon, J. \& Co-Authors (2010). "Using Global Arrays to Investigate Internal Waves and Mixing" in these proceedings (Vol. 2), doi:10.5270/OceanObs09.cwp.58.

37. Zhang, J., R. W. Schmitt and R. X. Huang, 1999. The relative influence of diapycnal mixing and hydrologic forcing on the stability of the thermohaline circulation. Journal of Physical Oceanography, 29(6), 1096-1108.

38. Hastenrath, S. L., 1976: Variations in low-latitude circulation and extreme climatic events in the tropical Americas. J. Atmos. Sci., 33, 202-215.

39. Marshall, J., Y. Kushnir, D. Battisti, P. Chang, A. Czaja, R. Dickson, J. Hurrell, M. McCartney, R. Saravanan, and M. Visbeck, 2001. Int. J. Climatol. 21: 1863-1898.

40. Karnauskas, K.B. and A.J. Busalacchi, 2009: The Role of SST in the East Pacific Warm Pool in the Interannual Variability of Central American Rainfall. J. Climate, 22, 2605-2623.

41. Shanahan, T. M., J. T. Overpeck, K. J. Anchukaitis, J. W. Beck, J. E. Cole, D. L. Dettman, J. A. Peck, C. A. Scholz, and J. W. King, 2009. Atlantic Forcing of Persistent Drought in West Africa. Science, 324 378-380.

42. Ummenhofer, C. C., M. H. England, P. C. McIntosh, G. A. Meyers, M. J. Pook, J. S. Risbey, A. S. Gupta, and A. S. Taschetto (2009), What causes southeast Australia's worst droughts?, Geophys. Res. Lett., 36, L04706, doi:10.1029/2008GL036801.
43. Freeland, H. \& Co-Authors (2010). "Argo - A Decade of Progress" in these proceedings (Vol. 2), doi:10.5270/OceanObs09.cwp.32.

44. Riser, S., L. Ren and A. Wong, 2008. Salinity in Argo: A modern view of a changing ocean. Oceanography, 20 (1), 56-67.

45. Lagerloef, G. \& Co-Authors (2010). "Resolving the Global Surface Salinity Field and Variations by Blending Satellite and In Situ Observations" in these proceedings (Vol. 2), doi:10.5270/OceanObs09.cwp.51.

46. Reverdin, G., P. Blouch, J. Boutin, P.P. Niiler, J. Rolland, W. Scuba, A. Lourenco, and A.F. Rios, 2007: Surface Salinity Measurements - COSMOS 2005 Experiment in the Bay of Biscay. J. Atmos. Oceanic Technol., 24, 16431654.

47. Delcroix, T., A. Dessier, Y. Gouriou, and M. McPhaden, 2005. Time and space scales for sea surface salinity in the tropical oceans. Deep-Sea Res. I, 52, 787-813.

48. McPhaden, M. \& Co-Authors (2010). "The Global Tropical Moored Buoy Array" in these proceedings (Vol. 2), doi:10.5270/OceanObs09.cwp.61.

49. Send, U. \& Co-Authors (2010). "Towards an Integrated Observing System: In Situ Observations" in these proceedings (Vol. 1), doi:10.5270/OceanObs09.pp.35.

50. Burnett, W. \& Co-Authors (2010). "Quality Assurance of Real-Time Ocean Data: Evolving Infrastructure and Increasing Data Management to Monitor the World's Environment" in these proceedings (Vol. 2), doi:10.5270/OceanObs09.cwp.12 